\title{
Uterine Corpus Non-Neoplastic Disorder
}

National Cancer Institute

\section{Source}

National Cancer Institute. Uterine Corpus Non-Neoplastic Disorder. NCI Thesaurus. Code C27624.

A non-neoplastic disorder that affects the uterine corpus. Representative examples include endometritis and uterine adenomyosis. 